\section{Heliocentric tangents}

SIR-The heliocentric hypothesis, so ably championed by Copernicus and Galileo ${ }^{1}$, is authoritatively said to have originated with Aristarchus of Samos in the third century BC. Sand-Reckoner, written by Aristarchus's younger contemporary Archimedes before $216 \mathrm{BC}^{2}$, attributed to Aristarchus a book containing the hypotheses "that the fixed stars and the sun remain unmoved, [and] that the earth revolves about the sun in the circumference of a circle, the sun lying in the middle of the orbit . . .". Aristarchus's (lost) book is thought to have "clearly . . . also included some kind of geometrical proof"'.

Aristarchus had also produced a treatise On the sizes and distances of the Sun and Moon, which has survived intact. Its "excellent" methodology confirms that Aristarchus's (probably later) heliocentric hypothesis was similarly "not irresponsible" but rather the work of a "conscientious astronomer"?

Nicholas Copernicus's De Revolutionibus (1543) acknowledged Aristarchus but not his heliocentric hypothesis ${ }^{4}$; however, it seems certain that Copernicus was also acquainted with the latter. For example, his original manuscript had referred to the opinion of Aristarchus on the movement of the Earth, but this reference was subsequently "suppressed" or "scored out". Moreover, in relating the views of Philolaus, Heracleides and Ecphantus on the question of movement of the Earth, Copernicus's Preface quoted from $\mathrm{De}$ Placitis Philosophorum of pseudoPlutarch, a work in which may also be found: "Aristarchus places the Sun among the fixed stars, and holds that the Earth moves around the Sun's circle" ${ }^{4}$. And $D e$ Revolutionibus (IV, 32) cites Archimedes' Measurement of the Circle, a treatise commonly found in the company of SandReckoner.

Copernicus's unquestionably pivotal contribution to astronomy was his grand revival of the heliocentric hypothesis as a systematic planetary theory ${ }^{+}$. But in order to fit theory to observations, Copernicus had retained the geometric devices used by Ptolemy (the deferent, epicycle and excentric), and had referred details of planetary movements not to the Sun but rather to the centre of the Earth's orbit. Because of technical and other difficulties with the copernican system, the astronomer Tycho Brahe (1546-1601) rejected it. Brahe had compiled an unrivalled set of observations, which he thought would demonstrate that the Sun and Moon travel around the Earth while the other planets travel round the Sun".

After Brahe's death, Johannes Kepler (1571-1630) invested years in the analysis of Brahe's data, culminating in the derivation of Kepler's three laws of planetary motion. These provided a precise and enduring mathematical characterization of the heliocentric hypothesis, thus serving to support the position of Copernicus while ironically refuting that of Brahe.

STUART HALE SHAKMAN

2269 Chestnut St, Apt 115.

San Francisco, California 94123, USA.

1. Nature 337, 101 (1989).

2. Sarton, G. A History of Science: Hellenistic Science and Culture in the Last Three Centuries BC, 54-57 (Harvard University, Cambridge, 1959).

3. Heath, T. Aristarchus of Samos, 301-302 (Clarendon, Oxford, 1913)

4. Armitage, A. Copernicus (Allen \& Unwin, London, 1938)

5. Heath, T. The Works of Archimedes xxiv-xxvi (Dover, New York, 1912).

6. Armitage, A. Sun Thou Stand Still 140, 169-175 (Sigma, London, 1947).

\section{CFC photolysis}

SIR-It is certainly possible (Nature 338, $100 ; 1989)$ that "the great Antarctic ozone hole is a place where [CFCs and their products are] washed out on to the icecap". But this is not the rate-limiting factor in the very long tropospheric lifetimes of CFCs. The rate-limiting factor is simply the rate at which CFCs are carried up into the stratosphere to be photolysed. The sites of this photolysis are the middle and high stratosphere outside the polar night, not the ozone hole; and all the evidence points to the conclusion that this rate is controlled by atmospheric dynamics and that it is not particularly sensitive to details of how and where photolysed material returns to the troposphere. If anything, the throughput could be a little weaker in strong ozone-hole years.

\section{University of Cambridge,}

Department of Applied Mathematics and Theoretical Physics,

Silver Street, Cambridge CB3 9EW, UK

\section{Status of science}

SIR-I agree with the gist of your leading article "Science squeezed" (Nature 338, 1; 1989) on the shortage of young researchers in Britain. Research should be shown to be an honoured as well as an honourable profession, but the salaries paid by the state are surely indicative of the public's view of the comparative standing of the profession, as we have recently seen in the case of nurses.

I would like to take hospital physicists as an example of the standing of scientists. They have recently accepted, under duress, a pay rise of only 5.5 per cent. whereas the medical profession has been awarded a rise of more than 8 per cent. This is a fairly typical experience for scientists employed by the National Health Service and the story could probably be repeated in other countries. I realize that hospital physicists are not predominantly engaged in research, but the country is tragically short of physicists in many areas. It is not surprising that there is now a substantial shortage of hospital physicists, yet the British public was only recently outraged when the calibration of an instrument used for radiotherapy in a hospital was wrongly set.

Lord Zuckerman, in Scientific American (September 1988, page 106), said that the most important element in the role of the scientific adviser to the chief executive (president or prime minister), is to "advise . . on whether or not the country's educational institutions are turning out enough adequately trained manpower to fill the jobs that determine the well-being of the nation. A president,

. has to feel confident that everything that can be done to satisfy this objective is being done, given the resources that can be made available." There is no evidence that this is happening in Britain.

PETER N. CAMPBELL

Department of Biochemistry,

University College London,

London WC1E 6BT, UK

\section{Reprint research}

SIR-Previous correspondents have argued for and against the reprint system, but have provided very little information about the pattern of reprint requests. You may therefore be interested in the sources of requests for reprints of my paper "Population dynamics of starlings in New Zealand" (N.Z. J. Ecol. 4, 65-72; 1981). Starlings, being cosmopolitan, should interest all countries; publication yielded a nice collection of stamps and the following tally: United States 24, Canada 4, Finland 4, France 4, Japan 4, Hungary 3, Spain 3, Sweden 3, Australia 2, Belgium 2. Czechoslovakia 2. East Germany 2, West Germany 2, Israel 2, Poland 2, Alaska 1, Denmark 1. Italy 1, Latvia 1. Mexico 1. South Africa 1. Soviet Union 1. United Kingdom 1.

Given these data, one may speculate. Has the Soviet Union 24 times as many Xerox machines as the United States, or has the United States 24 times as many starlings? What does the United States do with all these reprints when it is said that Americans never quote overseas literature? If only one in 24 Soviets reads English, what do the English read? The intense rivalry between East and West Germany is mirrored in the exactly similar number of reprint requests, but why the balance between Latvia and Mexico? Finally, look at New Zealand: 3 million people, and none could afford the stamp.

Ecology Division, DSIR

JOHn E. C. Flux

PO Box 30379 ,

Lower Hutt,

New Zealand 